\title{
A Belt and Road Initiative: uma análise sobre a projeção global da China no Século XXI
}

\author{
The Belt and Road Initiative: an analysis about China's \\ global projection in the 21st century
}

\section{La Iniciativa de la Franja y la Ruta: el análisis de la proyección global de China en el siglo XXI}

1. Bacharel em Relações Internacionais
pela UNIPAMPA, Mestre em Relações
Internacionais pela Universidade Fede-
ral de Santa Catarina (UFSC), Mestre em
Estudos da China Contemporânea pela
Renmin University of China e douto-
rando em Relações Internacionais pela
Universidade Federal de Santa Catarina
(UFSC). Orcid: https://orcid.org/00000003-0282-468X

\section{Professor Titular junto do Depar-} tamento de Economia e Relações Internacionais da UFSC (Universidade Federal de Santa Catarina). Professor da Pós-Graduação em Relações Internacionais da UFSC (PPGRI/UFSC). Doutor em Geografia pela UNESP/PP. Florianópolis, Santa Catarina, Brasil. Orcid: https:// orcid.org/0000-0001-7518-3356
Ricardo Lopes Kotz'

Helton Ricardo Ouriques²

DOI: 10.5752/P.2317-773X.2021v9.n2.p96

Recebido em: 22 de junho de 2020

Aceito em: 06 de setembro de 2020

\section{Resumo}

O presente artigo analisa o papel geoeconômico dos investimentos estrangeiros diretos da China para a execução da Belt and Road Initiative (BRI), o principal conceito de política externa do mandatário Xi Jinping. Para isto são propostos dois horizontes temporais que permitem realizar uma análise conjuntural acerca da inserção internacional da China: 40 anos e 20 anos. Estes recortes temporais abrangem o processo de reformas e abertura, à partir de 1978, passando pela projeção global dos investimentos chineses com a estratégia Going Global e que resulta atualmente na Nova Rota da Seda, ou Belt and Road Initiative. Os principais resultados da pesquisa sugerem que embora tenha surgido como um plano para a construção de infraestrutura através da Eurásia, a BRI se tornou um amplo conceito para se compreender a posição da China no sistema internacional, sobretudo na condução de suas relações com outros países emergentes. Os recortes temporais analisados representam uma continuidade na trajetória político-estratégica da China e visam à obtenção do seu principal objetivo de Estado: a continuidade do seu desenvolvimento econômico. O aporte teórico da geoeconomia é importante, neste trabalho, para compreender a implementação e consolidação da BRI através da emissão de investimentos estrangeiros diretos.

Palavras chave: Geoeconomia. China. Investimentos. Belt and Road Initiative. 
and Road Initiative. The main results of the article suggest that even though BRI was launched as a plan for building infrastructure across Eurasia, it has now become a broad concept for understanding China's position in the international system, especially in conducting its relations with emerging countries. The time frames analyzed show a continuity in China's political and strategic trajectory aiming at obtaining its main state objective: the continuity of its economic development. The theoretical contribution of geo-economics is important, in this article, in order to understand the implementation and consolidation of BRI through the issuance of foreign direct investments.

Keywords: Geoeconomics. China. Investments. Belt and Road Initiative.

\section{RESUMEN}

Este artículo examina el papel geoeconómico de la inversión extranjera directa de China en la implementación de la Belt and Road Initiative (BRI), el concepto principal de política exterior del presidente Xi Jinping. Para este propósito, se proponen dos horizontes de tiempo que permiten un análisis cíclico sobre la inserción internacional de China: 40 años y 20 años. Estos plazos cubren el proceso de reforma y apertura, comenzando en 1978, pasando por la proyección global de las inversiones chinas con la estrategia Going Global y que actualmente da como resultado la Nueva Ruta de la Seda, o la Belt and Road Initiative. Los principales resultados de la investigación sugieren que, aunque surgió como un plan para construcción de la infraestructura en toda Eurasia, BRI se ha convertido en un concepto amplio para comprender la posición de China en el sistema internacional, especialmente en la conducción de sus relaciones con otros países emergentes. Los plazos analizados representan una continuidad en la trayectoria político-estratégica de China y apuntan el principal objetivo estatal: la continuidad de su desarrollo económico. La contribución teórica de la geo-economía es importante, en este trabajo, para comprender la implementación y consolidación de BRI a través de la emisión de inversiones extranjeras directas.

Palabras clave: Geo-economía. China. Inversiones. Belt and Road Initiative.

Introdução

O ressurgimento da República Popular da China (RPC) no cenário internacional ${ }^{3}$ vêm demonstrando uma acelerada trajetória rumo à promoção do desenvolvimento econômico e social. Governado pelo Partido Comunista, o país tirou 800 milhões de pessoas da pobreza desde que começou o processo de reformas e abertura em 1978 (THE WORLD BANK, 2018).

Além disto, a renda per capita de sua população passou de menos de US\$ 1.000 no ano de 1978 para mais de US\$ 7.000 em 2018, sendo agora um país de renda média, com uma população de 1.4 bilhão de pessoas. A RPC representava 3\% da economia global quando o então mandatário Deng Xiaoping iniciou o processo de reformas e abertura econômica da nação e atualmente o seu PIB representa aproximadamente $19 \%$ do total mundial (CAI; GARNAUT; LIGANG, 2018, p. 7-12).

No que diz respeito à sua atuação internacional, o país afirmava desde o período de Deng Xiaoping a sua postura de baixo perfil (low profile), na qual a China se limitava a participar da ordem internacional, com foco na promoção do seu desenvolvimento econômico doméstico e sempre com uma postura pacífica e aparentemente sem aspirações de reforma ou quaisquer mudanças acerca do sistema internacional.
3. Fala-se em ressurgimento pois a 0 Império chinês foi a maior economia do mundo entre desde o século XVI, até o século XVIII. Medindo em termos de paridade de poder de compra, estima-se que a China representasse cerca de $33 \%$ da economia global em 1820 seguida pela Índia que representava erca de $18 \%$ do PIB mundial à época (STUENKEL, 2016, p. 37). 
4. 0 significado literal do termo em mandarim seria Um Cinturão, Uma Estrada. No entanto, devido à dificuldade de tradução em diversos idiomas o governo chinês incentiva o uso dos termos em inglês e/ou mandarim.

5. As fontes provenientes de think tanks são utilizadas devido ao fato de que a RPC não disponibiliza uma base de dados oficial com todos os projetos contidos na BRI
O ano de 2013 representa um ponto de inflexão e mudança, quando o mandatário Xi Jinping propôs a Nova Rota da Seda ou Belt and Road Initiative (Yi dai, Yi lu 一带一路 em mandarim) $)^{4}$, em um discurso proferido na cidade de Astana, no Cazaquistão. A Belt and Road Initiative (BRI) consiste em um plano para a construção de infraestrutura abrangendo mais de 70 países, $62 \%$ da população global, mais de $30 \%$ do PIB mundial e 75\% dos recursos energéticos disponíveis (THE WORLD BANK, 2018).

A trajetória bem-sucedida no desenvolvimento econômico ressalta a importância de que sejam produzidas análises críticas sobre a atuação internacional da China, sobretudo em um contexto no qual o país se posiciona de forma mais propositiva no cenário global. Após pouco mais de cinco anos de execução da BRI é possível realizar um balanço dos seus resultados iniciais.

A inserção internacional da China será analisada através de dois marcos temporais: 40 e 20 anos, demonstrando a linha de continuidade que vem desde o processo de reformas e abertura conduzido por Deng Xiaoping (1978), passando pelo marco da estratégia Going Global (2000) e chegando até a Nova Rota da Seda. O fio condutor e principal objetivo levado adiante pela China nesta trajetória é a busca pelo desenvolvimento econômico, visto como o aumento do PIB, da renda per capita, das condições de vida de sua população e da ascensão das empresas chinesas aos segmentos produtivos mais sofisticados das cadeias globais de valor.

Para isto analisaremos a BRI através do marco teórico da geoeconomia, uma das vertentes de análise dos estudos estrategicos e da teoria geopolítica contemporânea. A metodologia da pesquisa utiliza os procedimentos de revisão bibliográfica e análise documental, compreendendo o período de 2001-2019, buscando integrar a visão de teóricos ocidentais à visão de analistas chineses sobre o objeto proposto.

Utilizam-se igualmente documentos oficiais provenientes do governo da República Popular da China e de organismos internacionais, tais como os relatórios globais de investimentos publicados pela UNCTAD, além de ocasionalmente bases de dados provenientes de think tanks, para tentar mapear os investimentos ao longo da BRI ${ }^{5}$.

$\mathrm{O}$ artigo está estruturado da seguinte maneira: a primeira seção apresenta o marco teórico da geoeconomia, a segunda seção aborda o processo de abertura e reformas da China (1978) e a estratégia Going Global, que começa no ano de 2001. A terceira seção apresenta a Belt and Road Initiative. Nas considerações finais realiza-se a análise e discussão acerca da BRI e dos investimentos chineses sob a perspectiva da geoeconomia.

Instrumental teórico: a geoeconomia

As teorias tradicionais que explicam a alocação de investimentos externos diretos (IED), tais como as desenvolvidas por Hymer (1960) e Dunning (1988), por exemplo, não conseguem abarcar a totalidade da projeção global dos investimentos chineses. As limitações do poder explicativo destas teorias em relação à China ocorre em parte pelo contexto específico nos quais estas teorias foram elaboradas (MILAN; SANTOS, 2014) e, igualmente, pela singularidade do modelo econômico chinês, seja 
ele definido como um capitalismo de Estado (KROEBER, 2016) ou um socialismo de mercado (CAI, 2015).

Independentemente da nomenclatura específica a ser aplicada para denominar a economia chinesa, é fato de que se trata de um país que combina estruturas de mercado desenvolvidas e a forte presença do Estado na sociedade civil e nas atividades econômicas. Um exemplo disto reside no fato de que o setor privado emprega mais de $80 \%$ da população (WORLD BANK, 2018). Paralelamente a isto, a posse da propriedade sob a terra continua sendo estatal e as maiores empresas do país são estatais.

No ano 2000 a China possuía 10 empresas na lista da Fortune 500, que designa as maiores empresas do mundo. Ao final do ano de 2019 o país possuía 119 empresas na lista. Se as empresas de Taiwan forem consideradas, a China passa a possuir 129 empresas na lista citada, o que faria com que ultrapassasse as 126 empresas norte-americanas (FORTUNE, 2019), um fato inédito na história do capitalismo contemporâneo. Entre as 119 firmas listadas, $82 \%$ são estatais.

Neste sentido, o emprego de recursos geoeconômicos é um dos instrumentos que auxiliam na compreensão do caso chinês. A emissão de IED por parte de grandes empresas provenientes da China, sobretudo as estatais, acaba por corresponder simultaneamente a interesses de mercado (a busca pelo lucro), havendo intersecção com metas relacionadas ao interesse nacioal (MILAN; SANTOS, 2014).

Os estudos estratégicos empregam o conceito definido como geoeconomia, para evidenciar a relação entre fatores geográficos e o emprego de políticas econômicas. Este conceito evidencia o uso de recursos econômicos para atingir fins geopolíticos, ou metas correspondentes ao interesse nacional (BLACKWILL; HARRIS, 2016). Este é um importante conceito para compreender a atuação recente da China (HONG, 2016; XIAOYU, 2017). Em outras palavras, a geoeconomia pode ser vista como a continuação da geopolítica por outros meios. Fazemos nesta formulação uma clara alusão ao conceito desenvolvido por Clausewitz $Z^{6}$.

Outras definições incluem: "A geoeconomia é definida como o estudo dos efeitos e das causas materiais do poder e suas disputas entre os diferentes atores na ordem internacional" (MELLO, 2020, p. 24), com foco na dimensão econômica e refletindo a influência de fatores geográficos estruturais. Grevi (2011, p. 28) apresenta o seguinte conceito: "A geoeconomia abrange tanto a conversão de ativos econômicos em influência política quanto a mobilização de poder político para alcançar objetivos econômicos por meio de instâncias competitivas ou cooperativas."

O conceito de geoeconomia vem da geopolítica clássica, mas restringe a área ao referir-se sobretudo às interações, disputas e efeitos decorrentes da interação entre a economia e os fatores geogrtáficos. Luttvak (1990) foi o primeiro analista a abordar este conceito, transpondo a lógica dos conflitos militares (geopolítica) para a arena dos interesses econômicos, como uma forma de analisar as relações internacionais após o fim da Guerra Fria. O poder econômico é necessário para a expansão do poder militar e sua atuação geoestratégica. Portanto, não existe uma substituição entre geopolítica e geoeconomia, pois as análises são complementares.
6. A Guerra nada mais é do que a continuação da política por outros meios. 
Exemplos do emprego de políticas com efeito geoeconômico incluem: 1) a compra de títulos de dívida nacional de outras nações; 2) decisões de mudança nos parceiros comerciais, sobretudo no caso da compra e venda de recursos estratégicos; 3 ) a decisão de alocação de investimento estrangeiro direto ou de capital de curto prazo, podendo desestabilizar economias nacionais de menor porte, ou mesmo contribuir para o desenvolvimento econômico de outras; 4) a importância de determinada nação para o sistema financeiro global, que pode ser utilizada como elemento de barganha geoeconômica; 5) o uso do tamanho do mercado doméstico como fator de negociação, por exemplo, quando as empresas chinesas exigem a transferência de tecnologia ou o estabelecimento de joint ventures com empresas nacionais, para as empresas estrangeiras que queiram se estabelecer em seu território e explorar o seu mercado; 6) o estabelecimento de embargos comerciais; entre outros (BLACKWILL; HARRIS, 2016).

O crescimento econômico e tecnológico tornou a China uma potência regional com impacto geopolítico em toda a Eurásia. O país faz fronteira com 14 Estados e possui fronteira marítima direta com outros três (Japão, Filipinas, Coréia do Sul e Taiwan - não reconhecido pela China como um Estado independente). A população dos seus vizinhos gira em torno de dois bilhões de pessoas e a população da China é atualmente de 1.4 bilhão, fazendo com que cerca de metade da população global seja afetada pelas ações geoestratégicas deste país. Esta preponderância influencia igualmente as regiões da Ásia Oriental e da Eurásia como um todo (COHEN, 2015).

No caso particular da RPC, quatro interesses estratégicos principais são de importância fundamental para entender o comportamento internacional do país: 1) Manter a segurança e a integridade territorial do país, o que inclui evitar movimentos separatistas nas suas províncias à Oeste (FERDINAND, 2016; SORENSEN, 2015); 2) A manutenção da estabilidade do regime do Partido Comunista da China (PCC); 3) A manutenção do processo de desenvolvimento econômico e social (CAI, 2015; KROEBER, 2016; ROLLAND, 2017), 4) reforçar o argumento da ascensão e do desenvolvimento por vias pacíficas, evitando a percepção por parte da comunidade internacional de que a China seja uma ameaça ou tenha objetivos revisionistas em relação ao ordenamento global (BUZAN, 2014; DANNER, 2018; SHAMBAUGH, 2016).

A tradição estratégica da China favorece o pensamento de longo prazo e a acumulação de vantagens através dos anos. Isto se deve ao fato de que historicamente o Império chinês lidava com um duradouro sentimento de insegurança, devendo atuar simultaneamente com inimigos localizados em diversas fronteiras geográficas. Assim, a estratégia do Império era cercar os seus inimigos lentamente, através da sucessiva acumulação de vantagens relativas. A tradição estratégica chinesa, portanto, apresenta claras diferenças em relação à tradição estratégica Ocidental, que prima por vitórias decisivas e finais, ou atos de heroísmo (KISSINGER, 2011).

A flexibilidade estratégica do pensamento chinês visa evitar os confrontos diretos. Elaborando através da tradição do pensamento do estrategista Sun Tzu, Kissinger (2011) afirma que o objetivo do Império chinês 
era evitar o conflito armado, focando nos seus objetivos políticos e como eles se imiscuem com a condução tática e estratégica. Derrotar o objetivo político do adversário sem precisar atacá-lo seria o êxito máximo, reduzindo a sua posição e sua força de forma gradual (KISSINGER, 2011).

Elementos de realpolitik, ou seja, cálculos pragmáticos baseados em interesses, coadunam-se com princípios confucianos, como a necessidade de equilíbrio, valorização da harmonia, possibilidade de cooperação para ganhos mútuos, além do foco no aspecto moral da política, ou seja a ideia de atuar de forma a firmar um exemplo virtuoso (RUONAM, FENG, 2015). Estes fatores serão examinados com maior precisão na seção que trata da Nova Rota da Seda.

A Grande Estratégia da China no sistema internacional têm sido o de desenvolvimento e/ou ascensão pacífica. Este arcabouço político que partiu desde 1978 abrange a estratégia de desenvolvimento pacífico da China, surgida a partir da Doutrina de Política Externa de Deng Xiaoping, e continuou sob os mandatos de Jiang Zemin (1990-2002) e Hu Jintao (2002-2012) (BUZAN, 2014).

Neste contexto, a China deveria esconder suas forças e mostrar algumas de suas fraquezas, a fim de não incutir um sentimento de possível conflito em relação a outras potências. Segundo Danner (2018, p. 33), a estratégia de desenvolvimento pacífico da China poderia ser resumida pelos seguintes pontos:

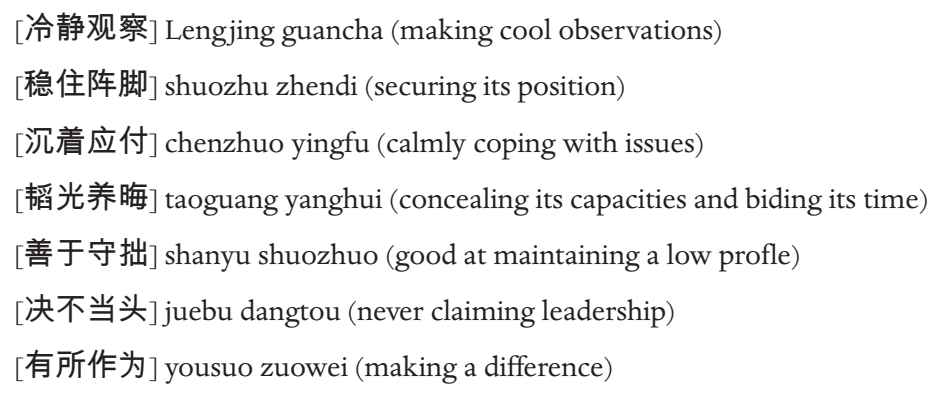

Grande Estratégia é um termo que compreende todos os planos e políticas de Estado, envolvendo o uso de recursos políticos, diplomáticos e econômicos para a obtenção dos interesses nacionais. Para além de elementos discursivos, o conceito de Grande Estratégia envolve ações práticas. Neste sentido:

\footnotetext{
A grande estratégia pode ser definida como a segurança geral a longo prazo e políticas externas de um estado territorial. A grande estratégia atende à interesses nacionais de um estado através do uso de todos os meios ddisponíveis para tal, ou seja, compreende as ferramentas econômicas, militares, diplomáticas, políticas, financeiras e de informação (DANNER, p. 2, 2018).
}

Silove (2018, p. 29), por outro lado, afirma que o conceito de Grande Estratégia possui três significados distintos e que cada um destes elementos apresenta um prisma analítico diferente, que pode contribuir para diferentes análises:

Primeiro, os estudiosos usam o conceito de grande estratégia para se referir a um plano deliberado e detalhado, elaborado por indivíduos. Segundo, eles o empregam para se referir a um princípio organizador que é conscientemente mantido e usado por indivíduos para orientar suas decisões. Terceiro, os estudiosos usam o termo para se referir a um padrão no comportamento de determinado Estado (SILOVE, 2018, p. 29). 
O conceito representa a gestão e o emprego dos recursos de um Estado com a finalidade de atingir seus interesses de longo prazo. A próxima seção abordará o processo de reformas e abertura da China, momento essencial de mudança político-econômica que contribuiu em grande medida para que o país atingisse os níveis de concentração de capital e desevolvimento sócio-econômico vistos atualmente.

As próximas secões abordarão as principais etapas da projeção internacional dos investimentos chineses, de modo a compreender o papel e as implicações desse instrumento geoeconômico para a atuação chinesa.

Os recortes de 40 e 20 anos: do processo de reformas e abertura de $1978 \dot{a}$ estratégia Going Global (2000)

A primeira fase dos investimentos estrangeiros diretos da China se situa entre os anos de 1979-1989, lançada através da Política de Portas Abertas de Deng Xiaoping. Durante a década de 1970 a economia chinesa apresentava crescentes dificuldades na condução de sua economia planificada, ligadas ao acesso e desenvolvimento de tecnologia.

A recepção de investimentos estrangeiros diretos, aliada à mobilização de recursos domésticos, foram fatores relevantes para as reformas da economia chinesa no final da década de 1970. Em 1978 o Conselho de Estado da China permitiu que as empresas do país estabelecessem subsidiárias no exterior, de modo a ter maior contato com tecnologias e sistemas econômicos externos, além de promover a imagem da China como um país que caminhava rumo à abertura (KROEBER, 2016).

Foram estabelecidas Zonas Econômicas Especiais (ZEEs), inicialmente na costa Leste, em Shenzhen, Zhuhai, Shantou (localizada na província de Cantão) e em Xiamen (localizada na província de Fujian). Posteriormente outras ZEEs foram estabelecidas no território chinês. Este consistiu no arcabouço institucional inicial que permitiu a entrada de empresas estrangeiras visando estimular o comércio, a recepção e a emissão de investimentos estrangeiros diretos (SHUJIE; PAN, 2014).

No ano de 1982 foi estabelecido o Ministério de Comércio Exterior e Cooperação Econômica (MOFTEC, na sigla em inglês), retirando do Conselho de Estado a atribuição de aprovar os investimentos chineses realizados no exterior. O órgão teve importante ação no sentido de padronizar os processos e práticas de emissão de investimento estrangeiro direto do país. Neste período, a maior parte das empresas chinesas que se internacionalizaram foram empresas estatais, visto que as médias e pequenas empresas serviam para o abastecimento do mercado local e ainda apresentavam baixo grau de diversificação industrial (FANG, 2015).

Visto que a demanda doméstica excedia a oferta de produtos e que a acumulação de capital do país no período era baixa, o grau de internacionalização de suas empresas era igualmente baixo. Os investimentos da China no exterior foram em sua grande maioria realizadas através do estabelecimento de entrepostos comerciais e escritórios de representação (WHARTON; YEH, 2016).

Os setores de mineração e agricultura concentraram a maior parte da destinação setorial dos investimentos externos da China no período 
de 1979-1984. Já no quinquênio 1985-1989, os investimentos se destinaram para as áreas de processamento e manufaturas básicas, e, em menor escala, para os setores de comércio, finanças e turismo. Além de destinos tradicionais, tais como os EUA, Macau, Hong Kong, Europa e Japão, a China começa, ainda que em menor escala, a investir em outros países da Ásia e igualmente na África e na América Latina. No ano de 1979 apenas quatro empresas chinesas realizavam investimentos no exterior, número que passou para 645 empresas emitindo investimentos estrangeiros diretos ao final do ano de 1989 (CHANGHONG; WEN, 2015, p. 23).

No ano de 1999 a emissão de investimentos chineses já alcançava quase 100 países, ao passo que nos anos 1980 os seus investimentos alcançavam apenas 45 Estados e demonstravam uma grande concentração em Hong Kong, Macau, a Europa Ocidental, os Estados Unidos e os países da região do sudeste asiático. Em 1999, foram realizadas emissões de investimento externo direto por 2.616 empresas chinesas (CHANGHONG; WEN, 2015, p. 27).

A estratégia Going Global surgiu através do $10^{\circ}$ Plano Quinquenal correspondente ao período 2001-2005, sendo que a sua deliberação previa a continuidade desta estratégia nos próximos planos quinquenais. $\mathrm{O}$ seu principal objetivo era a internacionalização de empresas chinesas que fossem competitivas, de modo a propiciar o aumento das exportações de produtos e serviços do país. A formulação do $11^{\circ}$ Plano Quinquenal correspondente ao período 2006-2010 menciona o aprofundamento da estratégia, enfatizando o aspecto de promoção de relações econômicas com benefícios para ambas as partes (win-win). O $11^{\circ}$ Plano enfatiza ainda a necessidade de adoção e adaptação aos princípios do ordenamento internacional e que a promoção do desenvolvimento deve ser o norte da economia chinesa (CENTRAL PEOPLE'S GOVERNMENT OF THE PEOPLE'S REPUBLIC OF CHINA, 2006).

No que diz respeito ao aspecto institucional, no ano de 2004 o MOFCOM publicou novos estudos acerca da internacionalização das empresas chinesas e foram estabelecidos mecanismos de incentivos fiscais específicos para aquelas que desejassem realizar investimentos estrangeiros diretos no exterior, através da padronização da ação do China EXIMBANK. No que diz respeito ao aspecto qualitativo, a década de 2000-2010 registrou o amadurecimento da internacionalização da China, ao passo que as empresas do país aumentaram a sua capacidade gerencial e consolidaram efetivamente o seu perfil transnacional. As estratégias de entrada em outros mercados também evoluíram ao passo que os seus investimentos passaram a abarcar, além de joint ventures, as fusões e aquisições, o capital de risco, o licenciamento de tecnologia, contratos de outsourcing e investimento greenfield, que corresponde à instalação de novas filiais de uma empresa partindo do zero em todos os seus processos operacionais (CHANGHONG; WEN, 2015).

A projeção global dos investimentos chineses (ou estratégia Going Global) foi inicialmente pensada como uma política visando o acesso a recursos naturais, sobretudo hidrocarbonetos, necessários para o desenvolvimento de sua economia nacional, tendo sido posteriormente diversificada para outros segmentos. A estratégia delineava três princi- 
pais objetivos: 1) aumentar a emissão de investimento externo direto; 2) melhorar a qualidade dos projetos de internacionalização das empresas domésticas; 3) reduzir progressivamente os controles de capital (OURIQUES, 2014).

Verificou-se um substancial aumento no estoque de investimento estrangeiro direto emitido pela China, que passou de US\$ 27.7 bilhões no ano 2000 (correspondendo ao lançamento da estratégia Going Global), para US\$ 1.306 trilhão no ano de 2018. Adicionalmente, Weidong e Dunford (2016, p. 331) afirmam que no ano de $2014,68 \%$ do estoque de IED da China se destinava para a Ásia. Os autores demonstram igualmente que neste mesmo ano, $87 \%$ do estoque de IED emitido pela China concentrava-se nos seguintes setores: serviços empresariais e financeiros; mineração; atacado e varejo; manufaturas industriais; transporte; serviços postais e de armazenamento.

Realizando uma ampla análise do período, é possível sinalizar os principais objetivos do processo de abertura e emissão de investimentos por parte da China: 1) garantir acesso à recursos naturais necessários para a manutenção do desenvolvimento econômico doméstico; 2) aumentar a competitividade das empresas chinesas, possibilitando a aquisição e desenvolvimento de tecnologia, através da integração destas empresas com o mercado internacional; 3) aumentar a influência da economia chinesa no mundo iniciando pelos países localizados no seu entorno e expandindo-se progressivamente para além da Ásia e abrangendo regiões como a África, a América Latina e a Europa.

A Belt and Road Initiative

É possível perceber o início de uma inflexão na formulação da estratégia internacional da China a partir do ano de 2010, quando o PIB do país superou o do Japão e surge a necessidade de um posicionamento mais incisivo no seu entorno regional. A partir de 2012, com o mandato do Presidente Xi Jinping, que iniciou em 2012, emerge a aspiração de concretizar uma postura mais propositiva no âmbito regional, sob os motes da busca pela realização (striving for achievement, no original) e o rejuvenescimento da nação chinesa (XUETONG, 2014).

Expandindo a estratégia Going Global, o mandatário chinês Xi Jinping lançou a Belt and Road Initiative (BRI) em 2013, que consiste em uma ampla visão acerca do posicionamento internacional da China. Inicialmente focada na construção de infraestrutura e no estímulo aos investimentos internacionais, atualmente a Iniciativa se ramificou para diversas áreas. Até o momento, o BRI compreende mais de 100 países, abrangendo mais de $62 \%$ da população mundial, $30 \%$ do PIB global e 75\% dos recursos energéticos disponíveis (THE WORLD BANK, 2019). A BRI se tornou a principal política externa da administração de Xi Jinping.

A BRI tem como objetivos o aumento da conectividade do espaço eurasiático, a alocação eficiente de recursos e a coordenação de políticas econômicas, de modo a promover uma arquitetura regional de cooperação que seja aberta, inclusiva e que estimule o desenvolvimento conjun- 
to dos países envolvidos no processo. Estes objetivos serão alcançados através da construção de capacidades, da cooperação financeira, da liberalização do comércio e de investimentos (STATE COUNCIL OF THE REPUBLIC OF CHINA, 2015).

A BRI compreende dois eixos principais: a Rota da Seda Marítima (Maritime Silk Road) e o componente terrestre, denominado Cinturão da Rota da Seda (Silk Economic Belt). Inicialmente, a BRI compreendia seis corredores econômicos: 1) a Nova Ponte Terrestre Eurasiática (que chegará ao território europeu); 2) o corredor econômico China-Mongólia-Rússia; 3) o corredor econômico China-Ásia Ocidental (chegando ao Oriente Médio); 4) corredor econômico China-Península da Indochina; 5) o corredor econômico China-Paquistão; e, finalmente, 6) o corredor econômico Bangladesh-China-Índia-Mianmar.

Em 22 de janeiro de 2018, na cidade de Santiago, Chile, a China convidou oficialmente a América Latina a participar da BRI. O governo chinês assinou 173 acordos de cooperação com 125 países e 29 organizações internacionais até março de $2019^{7}$. Os mapas abaixo apresentam os países membros da Iniciativa e os eixos terrestre e marítimo previstos no arcabouço da Nova Rota da Seda.

Imagem 1 - Mapa dos países membros da BRI (2019)
7. A Itália assinou um memorando de entendimento e de inclusão à BRI ao final de 2019, tornando-se o primeiro dos países desenvolvidos (membro do G7) a integrar a Iniciativa.
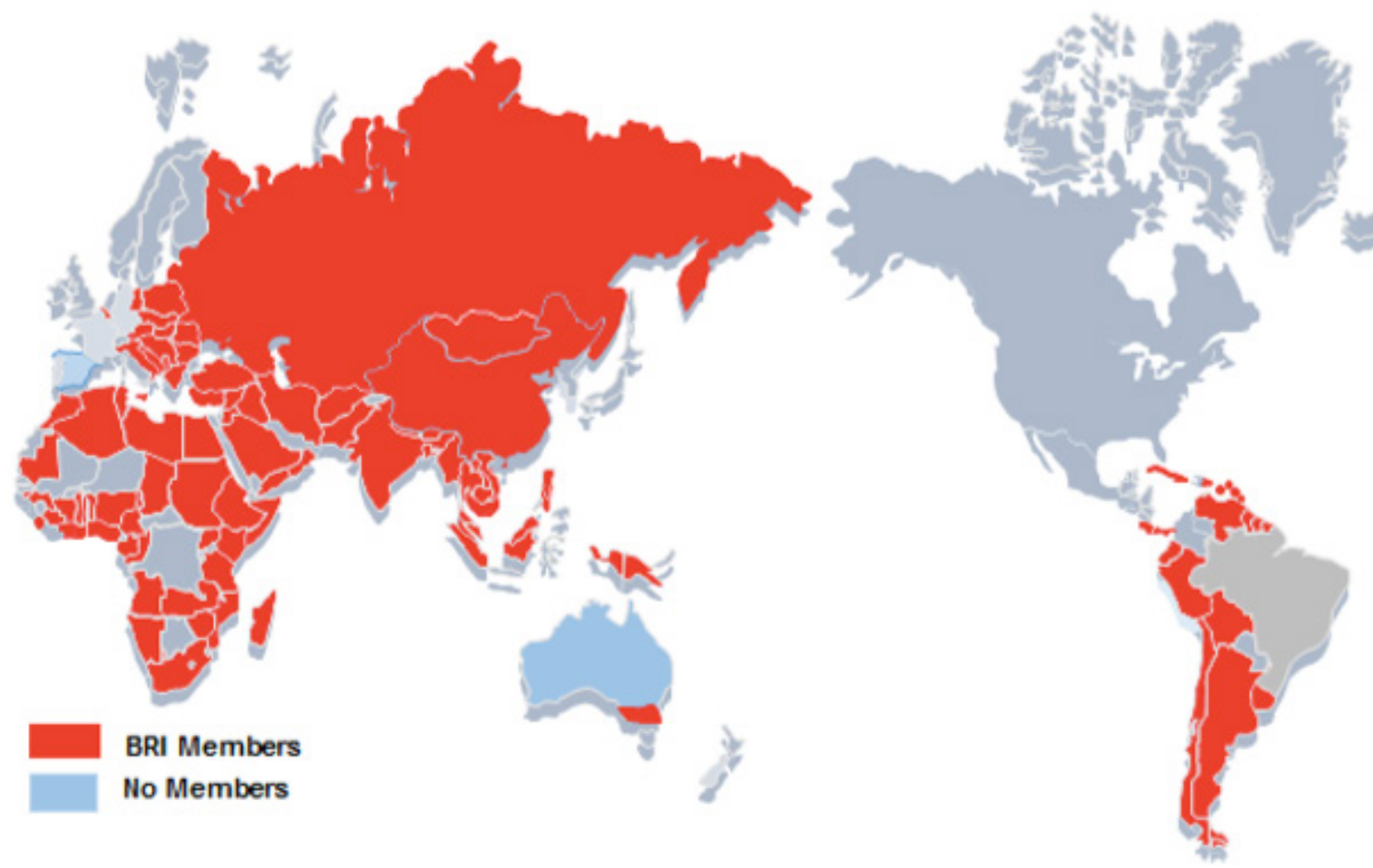

Fonte: GONZÀLES-SÀEZ (2019) 


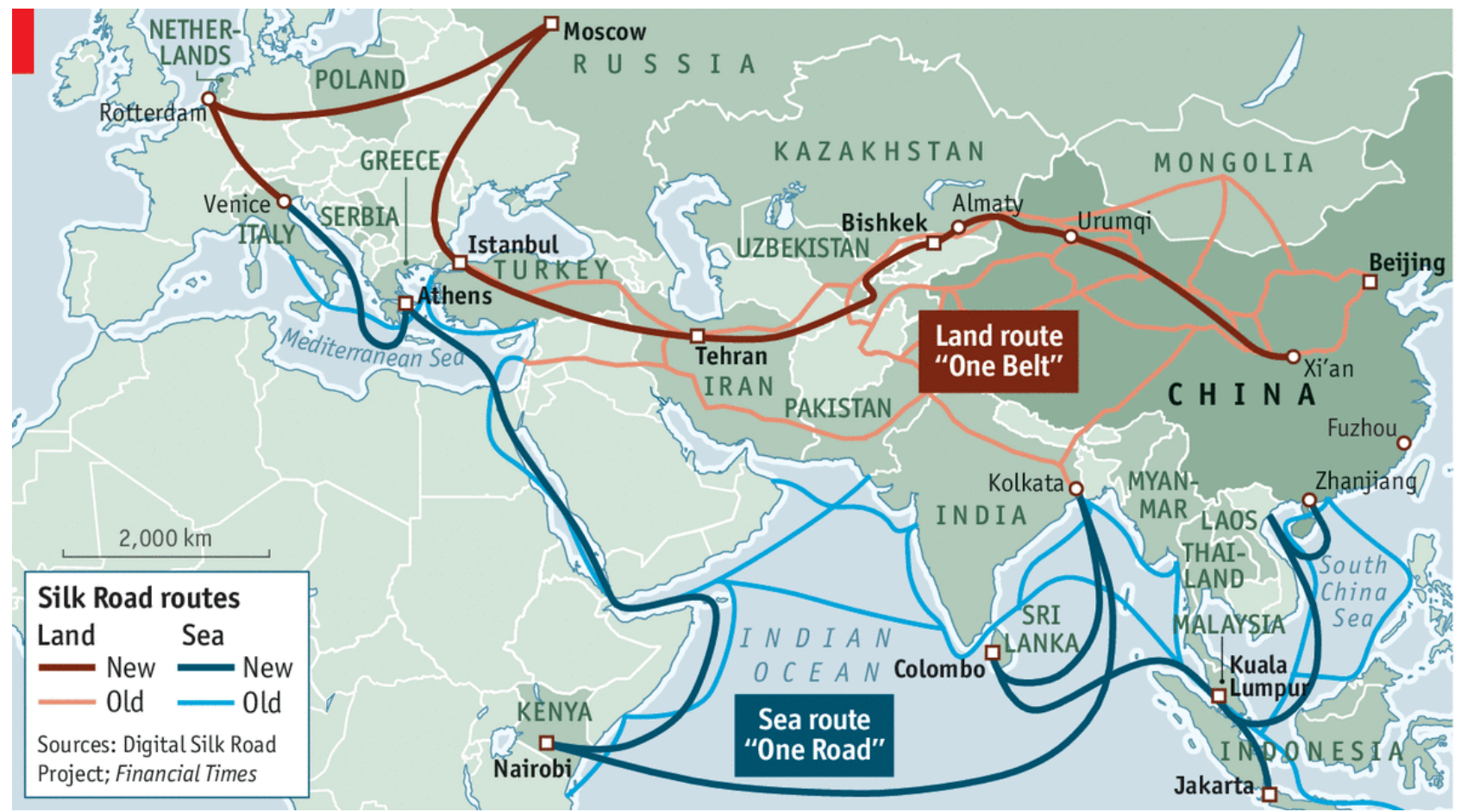

Fonte: The Economist (2016).

Para isto, a iniciativa possui cinco principais eixos de atuação: 1) comunicação; 2) conectividade (infraestrutura de transporte); 3) aumento dos fluxos monetários; 4) facilitação do comércio e 5) migração, visando à criação de uma área de cooperação que se estende desde o Pacífico Oeste indo até o mar Báltico (SARVÁRI e SZEIDOVICZ, 2016).

Os pronunciamentos do Governo chinês enfatizam a criação de um espaço de circulação de bens, ideias, pessoas e investimentos que seja aberto e multicultural, evocando o espírito da Rota da Seda (STATE COUNCIL OF THE PEOPLE'S REPUBLIC OF CHINA, 2015). Mantêm-se o discurso do desenvolvimento pacífico de Deng Xiaoping, mas claramente acrescenta-se a estes princípios um tom mais propositivo, apresentando uma contribuição da China para o ordenamento global.

Um exemplo disto pode ser visto nas informações trazidas pelo think tank chinês Center for China and Globalization (2017), demonstrando a visão de alguns analistas chineses sobre o tema:

\begin{abstract}
Wang Huiyao, presidente do Centro Independente para a China e a Globalização, diz que este é o novo motor da globalização [BRI]. Shen Digli, do Instituto de Estudos Internacionais da Universidade Fudan de Xangai, enfatiza a BRI como uma iniciativa de interconectividade em escala global. Wang Yiwei, do Centro de Estudos Europeus da Universidade Renmin, está convencido de que a BRI pode ser tão importante quanto a criação da União Europeia. E Shin Yinhong, do Centro de Estudos Americanos da Universidade Renmin, ressalta, fundamentalmente, que a OBOR / BRI não funcionaria se fosse meramente uma aposta geopolítica. (CENTER FOR CHINA AND GLOBALIZATION, 2017).
\end{abstract}

Além disso, as palavras de Xi Jinping (2017) também expressam o desejo de contribuir para a ordem mundial existente por meio da provisão de bens públicos globais, como financiamento para infraestrutura: 
Envidamos todos os esforços na busca de diplomacia dos principais países com características chinesas, promovendo a agenda diplomática da China de maneira abrangente, multinível e multifacetada e criando um ambiente externo favorável ao desenvolvimento da China. Buscamos conjuntamente a Iniciativa do Cinturão e Rota, iniciamos o Banco Asiático de Investimento em Infraestrutura, criamos o Fundo da Rota da Seda e organizamos o Primeiro Fórum do Cinturão e Rota para Cooperação Internacional, a $22^{\mathrm{a}}$ Reunião de Líderes Econômicos da APEC, a Cúpula do G20 2016 em Hangzhou, a Cúpula do BRICS em Xiamen e a Quarta Cúpula da Conferência sobre Medidas de Interação e Construção de Confiança na Ásia. A China defende o desenvolvimento de uma comunidade com um futuro compartilhado para a humanidade e incentivou a evolução do sistema de governança global. Com isso, vimos um aumento adicional na influência internacional da China, capacidade de inspirar e poder de moldar; e a China fez grandes novas contribuições para a paz e o desenvolvimento global (XI JINPING, 2017).

O China Global Investment Tracker (CGIT) estima que o IED chinês nos países da Nova Rota da Seda alcançou um estoque de US\$730.02 bilhões ao final de 2019. O setor de energia é o maior destino, acumulando US $\$ 283.33$ bilhões em IED, correspondendo por $38,8 \%$ do total, seguido pelo setor de transportes, que acumula 188.46 bilhões, representando $25.8 \%$ (CGIT, 2020).

O Corredor Econômico China-Paquistão (CPEC) é o eixo mais desenvolvido nos investimentos da BRI, sendo que foram inicialmente acordados 176 projetos de construção em diversas áreas, tais como usinas de energia, ferrovias, gasodutos, oleodutos e redes de cabos de fibra ótica. Estima-se que até 2030 sejam investidos US\$ 75 bilhões no CPEC (AHMAD; BHATTI; MUSTAFA, 2020).

O corredor econômico ligará a província de Xinjiang na China até o Porto de Gwadar, província de Baluchistan, no Paquistão, constituindo uma rede de rodovias e ferrovias em um trajeto de 3.218 quilômetros e contando com a construção de usinas energéticas ao longo do caminho. A conclusão do eixo econômico está prevista para o ano de 2030 e o mesmo encurtará em 12.000 quilômetros o trajeto de acesso da China em relação ao petróleo e gás natural proveniente do Oriente Médio, que na atual conjuntura passam em larga escala pelos Oceanos Índico e Pacífico (SYED; YING, 2020).

Além disto, já estão sendo estabelecidas 27 zonas econômicas especiais em diversas províncias do Paquistão, de modo a estimular o comércio internacional e prover incentivos para empresas que queiram se instalar nesses locais (SYED; YING, 2020).

Desta forma, a consolidação do CPEC evitaria a passagem de hidrocarbonetos pelo estreito de Malaca, na Malásia, uma região que pode ser facilmente bloqueada por navios militares, o que acarretaria vulnerabilidades geoestratégicas para a China no caso do acirramento de tensões com outras potências marítimas. Estima-se que o estoque de IED chinês no Paquistão durante o período de 2005-2019 seja de US\$ 56.3 bilhões (CGIT, 2020). Ou seja, se os investimentos do CPEC se consolidarem, o estoque de IED chinês no país quase dobrará na próxima década.

O estreitamento das relações com o Paquistão pode conceder uma rota de acesso para que as províncias situadas no Oeste da China se conectem ao Oceano Índico. Este movimento teria consequências estratégicas importantes para a região. Portanto, as relações com o Paquistão 
podem facilitar o acesso da China aos recursos energéticos provenientes do Oriente Médio e da África, além de constituir um importante aspecto de conexão entre os componentes marítimos e terrestres da BRI.

O Paquistão enfrenta problemas de falta de suprimento de energia, sobretudo no verão onde os apagões em regiões populosas são fatos recorrentes. Os projetos do CPEC auxiliarão a reduzir esta vulnerabilidade estrutural. Já existe um conjunto de projetos energéticos aprovados através de investimentos chineses que apontam para a geração de 10.400 Megawatts através de 14 usinas termais, eólicas, nucleares, solares e mesmo através da matriz energética de carvão (AHMAD; BHATTI; MUSTAFA, 2020).

Contrastando com o CPEC, eixo no qual a cooperação bilateral parece estar apresentando resultados satisfatórios para ambas as partes, existem casos onde a cooperação sob a BRI produz resultados controversos. No Sri Lanka, a China investiu cerca de US\$ 1.12 bilhão para a construção do porto de Hambantotta. Incapaz de sanar a dívida, o porto foi cedido para o uso da China, em uma concessão de 99 anos. Este fato sinaliza que a aceitação dos fundos da Nova Rota da Seda pela parte dos países de menor renda deve ser bem avaliada, de modo a evitar situações de vulnerabilidade (HILMAN, 2018).

Moramudali (2019), por outro lado, aponta que a maior parte da dívida do Sri Lanka foi contratada através de títulos negociados no mercado internacional, equivalendo a $39 \%$ da dívida. Por outro lado, a dívida para com a China equivale apenas a $10 \%$ do total da dívida nacional, segundo órgãos oficiais do Sri Lanka. Portanto, a dívida contraída para com a China teria sido o fator que terminou por desequilibrar a situação de um Estado que já estava endividado.

A consolidação de boas relações com os países situados no seu entorno estratégico, nomeadamente a Ásia Central, a Ásia Meridional e a Ásia Oriental, são essenciais para o processo de ascensão da China enquanto potência. Uma das ações desenvolvidas pela China consiste no esforço de projeção para o Oeste (KAI, 2016).

As dimensões marítimas e terrestres da BRI não possuem diferenciação explícita neste sentido, pois elas se retroalimentam e visam aumentar a influência da China nos espaços geoestratégicos do Oceano Pacifico e da Eurásia continental. Isto ocorre através do estabelecimento de hubs comerciais, através dos investimentos em infraestrutura e de esforços político-diplomáticos no sentido de formar maiores vínculos com os países da Eurásia (AOYAMA, 2016; LOBELL, 2016).

O discurso chinês visa enunciar uma mudança no pensamento estratégico tradicional de competição geopolítica para cooperação, através do aporte de recursos para o desenvolvimento, consolidando os seus interesses nacionais através de fluxos econômicos, o que corresponde ao exercício dos instrumentos da geoeconomia (BLACKWILL; HARRIS, 2016).

A BRI apresenta uma direção de longo prazo para a ação geoestratégica da China, devendo se estender pelos próximos 30-40 anos (HONG, 2016), sendo um dos eixos que podem contribuir para a ascensão da china como uma potência com suas próprias características (XIAOYU, 2017).

A construção de infraestrutura visando contribuir para o aumento da conectividade é uma das principais contribuições que a China aporta 
no âmbito regional, através de sua própria experiência econômica interna. Atingir o desenvolvimento econômico através da cooperação para ganhos mútuos (win-win) são a importante dimensão conceitual deste processo (DUNFORD e WEIDONG, 2016; XIAIOYU, 2017).

Consequentemente, a Nova Rota da Seda pode ser vista como um projeto pacífico, porém pragmático, de aumento da zona de influência da China em uma região de grande relevância geopolítica e econômica, como é o caso da Eurásia (PLOBERGER, 2017). Posteriormente a BRI se expandiu, chegando a englobar territórios além da massa terrestre eurasiática.

A ascensão de uma nova potência não depende exclusivamente do poder militar ou econômico, mas é influenciada pelos interesses e pelo modo como o poder é exercido, constituindo fundamentalmente um processo de barganhas e negociações. Neste caso, o conceito de potência em ascensão ou potência emergente é definido como um ator que precisa ser consultado para que haja mudança no status quo, mas que ainda não é capaz de determinar unilateralmente a sua própria agenda política para o âmbito sistêmico (NARLIKAR, 2013).

A BRI dependerá da aceitação pelos demais Estados participantes de que os preceitos pretendidos pela China atendem aos seus interesses. A abundância de recursos materiais não garante o exercício de influência ao longo da iniciativa. Assim, para ser bem-sucedida, deve haver uma noção geral de que os princípios promovidos pela China beneficiam os demais Estados que participem da BRI. Portanto, a resposta dos países membros será um importante condicionante para o sucesso da mesma. Os princípios servirão como base importante para que a BRI consiga efetivamente consolidar sua legitimidade (JI, 2015).

Entre os princípios delineados pela diplomacia chinesa, destaca-se a possibilidade de ganhos mútuos (win-win); o aumento da conectividade entre as nações; o crescimento dos fluxos de comércio e de investimentos que, por sua vez, levariam maior desenvolvimento aos países envolvidos. O resultado seria a criação de uma zona aberta de cooperação, integração e intercâmbios materiais e culturais, que o discurso oficial denomina como uma Comunidade com um Destino Comum (STATE COUNCIL OF THE PEOPLE'S REPUBLIC OF CHINA, 2015).

A criação da comunidade com um destino comum se refere a um projeto inclusivo para a posição internacional da China, que atuaria como um ponto central de articulação geoeconômica, provendo bens públicos para os países vizinhos e além. Isto se materializa através da noção de promoção do desenvolvimento pela via da construção de infraestrutura e adensamento do comércio e dos fluxos de investimento.

Tal visão faz referência à centralidade do Império chinês na articulação das rotas de comércio na Eurásia durante o período pré-moderno (antes do ano de 1453, ponto de desarticulação da Rota da Seda). O sistema sinocêntrico ou sistema imperial chinês possuía fundamentos materiais, através da força econômica e militar, mas se articulava com os vizinhos através de rituais e valores que consolidaram redes de comércio e interação, colocando a China no centro do sistema político-econômico asiático.

Este ordenamento era fundamentado igualmente através de princípios ideológicos e pela liderança política da China, que se propagava 
devido ao prestígio do Império chinês, a resiliência de sua cultura e a sua habilidade diplomática (QIN, 2012).

Por fim, embora tenha surgido como um plano para a construção de infraestrutura através da Eurásia, a Belt and Road Initiative é um amplo conceito para se compreender a posição da China no sistema internacional, sobretudo na condução de suas relações com outros países emergentes. Portanto, mais do que um plano específico, a BRI tornou-se uma nova forma, concreta, de compreensão das Relações Internacionais da China com o Sul Global.

Considerações Finais

A BRI materializa uma confluência de objetivos domésticos e internacionais da China, fator que a consolida como uma Grande Estratégia. No plano doméstico: 1) um estímulo à economia chinesa visando ao aumento das exportações de bens e serviços; 2) extensão do desenvolvimento chinês para o oeste e desenvolvimento de novos setores do seu tecido produtivo.

No plano internacional: 1) significa uma continuação da estratégia Going Global, lançada no ano 2000; 2) representa um componente estratégico de projeção política; 3) segundo a visão chinesa existe uma dimensão de contribuição à ordem internacional, através de bens públicos globais, auxiliando no desenvolvimento de países emergentes através da emissão de IED e da cooperação.

A BRI tem objetivos diversos dependendo da região onde esteja sendo executada. Ou seja: a forma de atuação e os objetivos da China na África, por exemplo, não serão os mesmos que na Europa Oriental ou na América Latina, por exemplo. A estratégia geoeconômica da China inclui a compra de empresas estrangeiras, adquirindo consequentemente a sua tecnologia, além de setores de pesquisa e desenvolvimento; como se observa de forma mais significativa na Europa (BLACKWILL; HARRIS, 2016).

Os investimentos chineses destinados à facilitação do acesso e escoamento aos recursos naturais de várias regiões tais como a Eurásia, a África e a América Latina, são outro exemplo de exercício da geoeconomia chinesa (OURIQUES, 2014). Incluindo igualmente a concessão de empréstimos aos mais variados Estados, como uma forma de promoção de boa vontade e da cooperação. Através dos seus investimentos a China vem consolidando uma robusta ferramenta diplomática para exercer influência e atingir seus objetivos estratégicos (BLACKWILL; HARRIS, 2016).

Neste sentido e tendo em mente as lentes de análise da geoeconomia e da grande estratégia chinesa, é possível afirmar que em relação à sua motivação, a emissão de investimentos externos diretos chineses tem motivações distintas dependendo do território: 1) pode ser resource seeking, buscando recursos naturais necessários para a manutenção do seu desenvolvimento econômico, 2) pode visar o posicionamento estratégico em setores econômicos de diferentes países; 3) significa inserção em mercados de porte e/ou que estejam em expansão; 4) implica a aquisição e desenvolvimento de tecnologia; 5) contribui para diferentes aspectos 
do poder nacional e consecução de interesses de Estado; 6) fortalece parcerias estratégicas com países de diversas regiões através da cooperação. Em termos de política externa a BRI é um conceito amplo, que traz a visão da China sobre a sua posição no sistema internacional.

Os líderes chineses atuais não possuem a legitimidade revolucionária para fundamentar sua continuidade no poder. Portanto, sob a perspectiva chinesa, a legitimidade do PCC vem do desenvolvimento econômico (KROEBER, 2016; LIBERTHAL, 2003; ROLLAND, 2017). A BRI, enquanto grande estratégia, está vinculada a esta lógica e os recursos geoeconômicos são uma importante ferramenta para a consolidação da Iniciativa.

Contudo, tendo uma visão mais ampla, acreditamos ser importante mencionar aqui algo que é preocupação teórica e empírica, e que nos motivará em pesquisas futuras. Arrighi (1997 e 2008) levantou a hipótese de que, depois de 500 anos de liderança econômica ocidental, a hegemonia estaria passando de mãos ocidentais para mãos não ocidentais. A centralidade cada vez maior da China nos processos de acumulação de capital, como herdeira do gigantesco processo de desenvolvimento regional iniciado pelo Japão após a Segunda Guerra Mundial (e seguido por Coreia do Sul e Tigres Asiáticos), está sendo colocada em outro patamar com a Belt and Road Initiative. Resta saber se isso significará, também, a ampliação da acumulação de poder. Se a resposta for positiva, estariam dadas as condições para o surgimento de uma nova hegemonia no sistema interestatal.

Referências

AHMAD, Farzad; BHATTI, Muhammad Nawaz; MUSTAFA, Ghulam. China Pakistan Economic Corridor: prospects and challenges. Pakistan Social Sciences Review. [s.l.], v. 4, n. 1, p. 293-305. mar. 2020.

AOYAMA, Rumi. "One Belt, One Road”: China's new global strategy. Journal Of Contemporary East Asia Studies. [s.l.], v. 5, n. 2, p. 3-22. 28 mar. 2017. Disponível em: https://www.tandfonline. com/doi/pdf/10.1080/24761028.2016.11869094?needAccess=true\&. Acesso em: 20 dez. 2019.

ARRIGHI, Giovanni. A ilusão do desenvolvimento. Petrópolis: Vozes, 1997.

ARRIGHI, Giovanni. Adam Smith em Pequim: origens e fundamentos do século XXI. São Paulo: Boitempo, 2008.

BLACKWILL, Robert D.; HARRIS, Jennifer M. War by Other Means: Geoeconomics and Statecraft. London: Belknap Press of Harvard University Press, 2016.

BUZAN, Barry. The Logic and Contradictions of 'Peaceful Rise/Development' as China's Grand Strategy. The Chinese Journal Of International Politics. [s.l.], v. 7, n. 4, p. 381-420, 03 jun. 2014. Disponível em: https://doi.org/10.1093/cjip/pou032. cesso em: 10 maio 2020.

CENTER FOR CHINA AND GLOBALIZATION. China Widens its Silk Road to the World. Disponível em: http://en.ccg.org.cn/china-widens-its-silk-road-to-the-world/. Acesso em: 10 Jan. 2020.

CENTRAL PEOPLE'S GOVERNMENT OF THE PEOPLE'S REPUBLIC OF CHINA. XI Plano Econômico Quinquenal da República Popular da China, 2006. Disponível em: https://policy. asiapacificenergy.org/sites/default/files/11th\%20Five-Year\%20Plan\%20\%282006-2010\%29\%20 for $\% 20$ National $\% 20$ Economic $\% 20$ and $\% 20$ Social $\% 20$ Development $\% 20 \% 28$ EN $\% 29$.pdf. Acesso em 17 Nov. 2019.

CHANGHONG, Pei; WEN, Zhegn. China Outbound Foreign Direct Investment Promotion System. New York: Springer, 2015.

CLAUSEWITZ, Carl Von. Da Guerra. São Paulo: Martins Fontes, 2010.

COHEN, Saul Bernard. Geopolitics: the Geography of International Relations. United Kingdom: Rowman and Littlefield, 3 ed., 2015. 
DANNER, Lucas K.. China's Grand Strategy Contradictory Foreign Policy? United Kingdom: Palgrave Mcmillan, 2018.

DUNNING, John. The Eclectic Paradigm of International Production: A Restatement and some Possible Extensions. In: Journal of International Business Studies,v. 19,n. 1, p. 1-31, jun. 1988

FANG, Cai. Desmistifying China's Economy Development. Spinger: China insights, 2015.

FENG, Zhang. Confucian Foreign Policy Traditions in Chinese History. The Chinese Journal Of International Politics. [s.l.], v. 8, n. 2, p. 197-218, 13 maio 2015. Disponível em: https://doi. org/10.1093/cjip/pov004. Acesso em: 24 set. 2019.

FERDINAND, Peter. Westward Ho: The China Dream and the One Belt One Road: Chinese foreign policy under Xi Jinping. International Affairs. [s.l.], v. 92, n. 04, p. 941-957, 20 jun. 2016. Disponível em: https://doi.org/10.1111/1468-2346.12660. Acesso em: 17 de abril de 2020.

FORTUNE GLOBAL 500. Fortune, 2020. Disponível em: https://fortune.com/global500/2019/ china-resources-national/. Acesso em: 17 abril 2020.

GARNAUT, Ross; LIGANG, Song; FANG, Cai. China's 40 years of Reform and Development: 1978-2018. Australia: Australian National Press, 2018.

GONZÁLEZ-SÁEZ, Ruvislei. The Chinese Project "One Belt One Road" Toward Latin America and the Caribbean. Economic-financial implications. Journal Of Evolutionary Studies In Business. [s.l.], v. 4, n. 2, p. 108-131. dez. 2019. Disponível em: https://revistes.ub.edu/index.php/ JESB/article/view/j062/29358. Acesso em: 12 mar. 2020.

GREVI, Giovanni. Geo-Economics and Global Governance. In: MARTININGUI, Ana; YOUNGS, Richard (eds.). Challenges for European Foreign Policy in 2012: What Kind of Geo-Economic policy will Europe implement? Madri: Fride, 2011.

HILMAN, Jonthan. A Game of Loans: How China Bought Hambantotta. In. SZECHENYI, Nicholas. China's Maritime Silk Road: strategic and economic implications for the Indo Pacific Region. Disponível em: https://csis-prod.s3.amazonaws.com/s3fs-public/publication/180404_ Szechenyi_ChinaMaritimeSilkRoad.pdf?yZSpudmFyARwcHuJnNx3metxXnEksVX3. Acesso: 15 jun. 2020.

HONG, Yu. Motivation behind China's 'One Belt, One Road' Initiatives and Establishment of the Asian Infrastructure Investment Bank. Journal Of Contemporary China. [s.l.], v. 26, n. 105, p. 353-368. 01 nov. 2016. Disponível em: https://doi.org/10.1080/10670564.2016.1245894. Acesso em: 03 março 2020.

HYMER, S.H. The International Operationsc of National Firms: A Study of Direct Foreign Investment, 1960. Tese (Doutorado em Economia) - MIT Library, Cambridge, 1960

JINPING, Xi. Full text of Xi Jinping's report at $19^{\text {th }}$ CPC National Congress. Xinhua/China Daily, 2017. Disponível em: http://www.chinadaily.com.cn/china/19thcpcnationalcongress/2017-11/04/content_34115212.htm. Acesso em: 12 jan. 2020.

JI, Miao. Expectations and Realities: managing the risks of Belt and Road Initiative. China Quarterly of International Strategic Studies, v. 1, n. 3, p. 497-522, 2015.

JINPING, Xi. The Governance of China Vol. II. Foreign Languages Press Co. Beijing: Beijing Press, 2017.

KAI, He. China's bargaining strategies for a peaceful accommodation after the Cold War. In: PAUL, T. V. (ed.). Accommodating Rising Powers: Past, Present, Future. United Kingdom: Cambridge University Press, 2016.

KISSINGER, Henry. On China. New York: Penguim Press, 2011.

KROEBER, Arthur R. China's Economy: what everyone needs to know. United Stated of America: Oxford University Press, 2016.

LIEBERTHAL, Kenneth. Governing China: from revolution through reform. [s.l.]: W. W. Norton \& Company, 2003.

LOBELL, Steven E. Realism, Balance of Power and Power Transitions. In: PAUL, T. V. (ed.). Accommodating Rising Powers: Past, Present, Future. United Kingdom, Cambridge University Press, 2016.

MORAMUDALI, Umesh. Is Sri Lanka Really a Victim of China's 'Debt Trap'? The Diplomat. [s.l.], 14 mai. 2019. Disponível em: https://thediplomat.com/2019/05/is-sri-lanka-really-a-victim-of-chinas-debt-trap/. Acesso em: 15 jun. 2020. 
NARLIKAR, Amrita. Negotiating the rise of new powers. International Affairs, Oxford, v. 89, n. 3, p. 561-576, maio 2013. Disponível em: https://www.jstor.org/stable/23473843. Acesso em: 10 Março 2020.

OURIQUES, Helton Ricardo. As relações econômicas entre China e África: uma perspectiva sistêmica. Carta Internacional, Belo Horizonte, v. 9, n. 1, p. 19-43, out. 2014. Disponível em: https://cartainternacional.abri.org.br/Carta/article/view/122. Acesso em: 7 dez. 2019.

ROLLAND, Nadège. China’s Eurasian Century? Political and Strategic Implications of the Belt and Road Initiative. National Bureau of Asian Research, 2017. Disponível em: http://www.nbr. org/publications/issue.aspx?id=346. Acesso em: 15 Jan. 2020.

RUONAM, Liu. FENG, Liu. To Ally or not to Ally? Debating China's non-Alliance Strtegy in the $21^{\text {st }}$ Century. How China Sees the World. Grifith/Tsinghua University Asia Institute, 2017.

SANTOS, Leandro Teixeira dos; MILAN, Marcelo. Determinantes dos Investimentos Diretos Externos Chineses: aspectos econômicos e geopolíticos. Contexto Internacional, Rio de Janeiro, v. 36, n. 2, p. 457-486, dez. 2014. Disponível em: https://doi.org/10.1590/S010285292014000200005. Acesso em: 18 Março 2020.

SHUJIE, Yao; PAN, Wang. China's Outward Foreign Direct Investments and Impact on the World Economy. Basingstoke: Palgrave Macmillan, 2014.

SILOVE, Nina. Beyond the Buzzword: The Three Meanings of "Grand Strategy". Security Studies, v. 27, n. 1, p. 27-57, 28 ago. 2017. Disponível em: https://doi.org/10.1080/09636412.2017.136 0073. Acesso em: 18 abril 2020.

SORENSEN, Camilla T.N. The Significance of Xi Jinping's "Chinese Dream" for Chinese Foreign Policy: From "Tao Guang Yang Hui” to "Fen Fa You Wei”. Journal of China and International Relations, v.3, n.1, p. 53-73, 29 maio 2015. Disponível em: https://doi.org/10.5278/ojs.jcir. v3i1.1146. Acesso em: 15 abril 2020.

SYED, Jawad; YING, Yung-Hsiang (ed.). China’s Belt and Road Initiative in a Global Context. [s.l.]: Palgrave Macmillan, 2019.

STATE COUNCIL OF THE REPUBLIC OF CHINA. Chinese Enterprises enter "Go Global” Era 4.0. The State Council of the People's Republic of China. Disponível em: http://english.gov. cn/news/top_news/2016/04/11/content_281475325205328.htm. Acesso em: 16 ago. 2019.

STATE COUNCIL OF THE REPUBLIC OF CHINA. Vision and Actions on Jointly Building Silk Road Economic Belt and 21st-Century Maritime Silk Road. The State Council of the People's Republic of China. Disponível em: http://english.gov.cn/archive/publications/2015/03/30/ content_281475080249035.htm. Acesso em: 16 ago. de 2019.

THE WORLD BANK. Country Overview: People's Republic of China (2020). The World Bank. Disponível em: https://www.worldbank.org/en/country/china/overview. Acesso em 15 jan. 2020.

THE WORLD BANK. Regional Integration: The Belt and Road Initiative. The World Bank. 2018. Disponível em: https://www.worldbank.org/en/topic/regional-integration/brief/belt-and-road-initiative. Acesso em: 15 jan. 2020.

UNCTAD STAT. Statistics Data Center. UNCTAD STAT. Disponível em: http://unctadstat. unctad.org/EN/Index.html. Acesso em: 20 dez. 2017.

WEIDONG, Liu; DUNFORD, Michael. Inclusive globalization: unpacking China's Belt and Road Initiative. Taylor\&Francis, v. 1, n. 3, p. 323-340, 28 set. 2016. Disponível em: https://doi.or $\mathrm{g} / 10.1080 / 23792949.2016 .1232598$. Acesso em: 03 jan. 2020

XIAOYU, Pu. One Belt, One Road: Visions and Challenges of China's Geoeconomic Strategy. ResearchGate, jan. 2017. Disponível em: https://www.researchgate.net/profile/Xiaoyu_Pu2/ publication/312533416_One_Belt_One_Road_Visions_and_Challenges_of_China’s_Geoeconomic_Strategy/links/5880fa00aca272b7b441711e/One-Belt-One-Road-Visions-and-Challenges-of-Chinas-Geoeconomic-Strategy.pdf. Acesso em 26 set. 2019.

XUETONG, Yan. From Keeping a Low Profile to Striving for Achievement. The Chinese Journal Of International Politics. [s.l.], p. 153-184. 22 abr. 2014. Disponível em: https://doi. org/10.1093/cjip/pou027. Acesso em: 26 set. 2019.

YEH, Emily; T, WHARTON, Elizabeth. Going West and Going Out: models in Chinese development. Taylor\&Francis, v. 57, n.3, p. 286-315, 3 out. 2016. Disponível em: https://doi.org/10.108 0/15387216.2016.1235982. Acesso em: 03 Março 2020. 